\title{
Intra- and intermolecular events direct the propeptide-mediated maturation of the Candida albicans secreted aspartic proteinase Sap1p
}

\author{
S. Beggah, ${ }^{1}$ B. Léchenne, ${ }^{1}$ U. Reichard ${ }^{2}$ S. Foundling ${ }^{3}$ and M. Monod ${ }^{1}$
}

Author for correspondence: M. Monod. Tel: +41 21314 0376. Fax: +41 213140378. e-mail: Michel.Monod@chuv.hospvd.ch

1 Service de Dermatologie (DHURDV), Laboratoire de Mycologie, BT422, Centre Hospitalier Universitaire Vaudois, 1011 Lausanne, Switzerland

2 Department of Medical Microbiology, Institute of Hygiene, University of Göttingen, Germany

3 Department of Medical and Organic Chemistry, School of Pharmacy, University of Wisconsin Madison, USA
Pathogenic yeasts of the genus Candida secrete aspartic proteinases (Sap) which are synthesized as preproenzymes. Expression of the C. albicans SAP1 gene lacking the propeptide-coding region in the methylotrophic yeast Pichia pastoris does not lead to the secretion of the enzyme into the culture supernatant, but results in an accumulation of recombinant protein in the cell. Co-expression in this system of the unattached propeptide from Sap1p, as well as from other Saps, restored Sap1p secretion. A deletion analysis revealed that only a 12 aa sequence in the propeptide, corresponding to a highly conserved region in all Sap propeptides, was necessary and sufficient to produce a large amount of Sap1p in culture supernatant. No Sap1p was secreted when Sap1p was produced with a propeptide carrying an $F$ to $D$ mutation in the identified 12 aa sequence. However, the simultaneous production of equivalent amounts of Sap1p and His-tagged Sap1p $\left(\mathrm{H}_{6}-\mathrm{Sap} 1 \mathrm{p}\right)$ with a mutated and a non-mutated propeptide, respectively, led to the secretion of both proteins in a ratio of approximately 1:2. The restoration of Sap1p secretion occurred at the expense of secretion of $\mathrm{H}_{6}$-Sap1p since the total activity was comparable to that of strains producing only $\mathrm{H}_{6}$-Sap1p with a non-mutated propeptide. In contrast, the proteolytic activity of strains secreting Sap1p and $\mathbf{H}_{6}$-Sap1p both with a functional propeptide was twice that of strains producing either Sap1p or $\mathbf{H}_{6}$ Sap1p alone, and the two enzymes were found in an equivalent amount in the culture supernatant. Altogether, these results show that the propeptide can only function once and that the maturation of recombinant $C$. albicans secreted aspartic proteinase Sap1p is directed through a combination of intraand inter-molecular pathways.

Keywords: SAP1 gene, protein secretion, signal peptides, recombinant proteins, Pichia pastoris

\section{INTRODUCTION}

The secreted aspartic proteinases (Saps) of the opportunistic pathogens of the genus Candida are of particular interest because of their role as virulence factors (Fallon et al., 1997; Borg-von Zepelin et al., 1998; Schaller et al., 1998, 1999). In C. albicans, they are encoded by a gene family with at least nine members,

Abbreviations: Sap, secreted aspartic proteinase; $\mathrm{H}_{6}$-Sap1p, $\mathrm{His}_{6}$-tagged Sap1p.
SAP1 to SAP9 (Monod et al., 1994, 1998). To date, only one gene from C. tropicalis (SAPT1; Togni et al., 1991) and two from C. parapsilosis (SAPP1 and SAPP2; de Viragh et al., 1993) have been cloned and sequenced, although preliminary investigations support the existence of more SAP genes in both species (Monod et al., 1994). The Candida Saps, like many other microbial secreted proteinases, are synthesized as precursors in a preproprotein form. The prepeptide, or signal peptide, of 16-18 aa residues is necessary for entry into the secretory pathway by transporting the protein across the membrane of the endoplasmic reticulum (Pfeffer \& 
Rothman, 1987). With the exception of Sap7p, which has a putative 195 aa propeptide, the Candida Saps have a relatively short propeptide (32-58 aa) which contains one to four KR sequences, one of which is located immediately before the $\mathrm{N}$-terminus of the mature part of the proenzyme.

The propeptide of many secreted proteinases has been found to be essential and specific for assisting correct folding as well as secretion of the mature domain of the enzyme (for a review, see Eder \& Fersht, 1995). Upon completion of folding, the propeptide is cleaved and removed to generate the active enzyme through an autoproteolytic reaction or, as in the Candida Saps, through an exogenous proteolytic reaction in the Golgi apparatus via the membrane-bound proteinase Kex2p (Togni et al., 1996; Newport \& Agabian, 1997), which specifically cleaves peptides after KR sequences (Julius et al., 1984). Two different conformations of the mature part of a protein can be obtained with two different prosequences (Shinde et al., 1997). Indeed, the mature part of subtilisin E was shown to be folded in an altered conformation through a mutated prosequence, resulting in differences of secondary structure, thermostability and substrate specificity.

It has been clearly established by many examples in vitro and/or in vivo that the propeptide can also mediate the folding of the proteinase when added as a separate polypeptide chain (Ohta et al., 1991; Fabre et al., 1992; Fukuda et al., 1994; McIver et al., 1995; van den Hazel et al., 1994). In vitro, the propeptide covalently attached to the mature domain of prosubtilisin $\mathrm{E}$ has been found to function intermolecularly as folding catalyst, although a parallel intramolecular pathway has not been ruled out (Zhu et al., 1989; Hu et al., 1996). However, whether the maturation of secreted proteinases occurs through inter- or intramolecular events has never been investigated in vivo. This question instigated our detailed analysis of the function of the Sap propeptide in the secretion of the mature enzyme. Our study on C. albicans Sap1p was carried out using the methylotrophic yeast Pichia pastoris expression system, which allows the production of substantial amounts of recombinant fungal proteinase (Borg-von Zepelin et al., 1998). We show here that recombinant Sap1p maturation is guided by the propeptide in a combination of intra- and intermolecular processes, and that only a 12 aa sequence in the propeptide is necessary and sufficient to completely ensure the secretion of active enzyme.

\section{METHODS}

Organisms and plasmids. Escherichia coli DH5 $\alpha$ was used for transformation and propagation of the recombinant plasmids. The E. coli-P. pastoris shuttle vector pPICZ $\alpha \mathrm{A}$ was provided with the $P$. pastoris expression system from Invitrogen. The low-copy-number plasmid pKJ113 has been previously described (Borg-von Zepelin et al., 1998). The P. pastoris strains GS115 and KM71 (Invitrogen) were used as transformation hosts.
Construction of the expression plasmids. Expression plasmids were constructed by cloning a SAP PCR product in the multiple cloning site of pKJ113 and pPICZ $\alpha \mathrm{A}$. Custom-made primers were provided by Microsynth (Balgach, Switzerland). PCR buffers and AmpliTaq polymerase were from Perkin Elmer Applied Biosystems. The buffer composition was $10 \mathrm{mM}$ Tris/HCI (pH 8.3), $50 \mathrm{mM} \mathrm{KCl}$ with $1.5 \mathrm{mM} \mathrm{MgCl}_{2}$, containing $0.2 \mathrm{mM}$ each $\mathrm{dNTP}$ and $2.5 \mathrm{U}$ polymerase per reaction. The PCR was carried out in a GeneAmp PCR system 2400 (Perkin Elmer Applied Biosystems) with a first denaturation step of $5 \mathrm{~min}$ at $94^{\circ} \mathrm{C}$ followed by 25 cycles of annealing at $55^{\circ} \mathrm{C}$ for $30 \mathrm{~s}$, elongation at $72{ }^{\circ} \mathrm{C}$ for $30 \mathrm{~s}$ and denaturation at $94^{\circ} \mathrm{C}$ for $30 \mathrm{~s}$. PCR was completed by a final elongation step at $72{ }^{\circ} \mathrm{C}$ for $10 \mathrm{~min}$. DNA from plasmids containing individual $S A P$ genes was used as template. The PCR products were purified using a PCR purification kit (Roche Diagnostics) and were digested by restriction enzymes for which a site (XhoI, BamHI or NotI) was previously designed at the $5^{\prime}$ extremity of the primers. The digested PCR products were then cloned into the appropriate sites of the multiple cloning site of the E. coli-P. pastoris shuttle vector.

The following pairs of sense and antisense primers were used to construct plasmids pSB10, pSB11, pSB42 and pSB249 (Tables 1 and 2), respectively, restriction sites underlined: GATGCTCGAGCAGCTAAAAGATCCCCAGGT and CAAAGGATCCTAGGTAAGAGCAGCAATGTT; GACGCTCGAGAAGCCATCCCAGTTACTTTAAAT and CAAAGGATCCT A GGT A A GA GCA GCAA TGTT; T T CCTCGAGAAAAGATCTCCAGCTAAAAGATCC and GTAGCGGCCGCTCTATCTTTTAACTTTACCTTCTTG; GCACTCGAGAAAAGATCTCCAGCTAAAAGATCCCCAGG and GCAGGATCCCTAGTGATGGTGATGGTGATGGGTAAGAGCAGCAATGTT. Plasmidic SAP1 DNA (Hube et al., 1991; Monod et al., 1994) was used as template. pKJ113 was used to generate pSB10 and pSB11, and pPICZ $\alpha \mathrm{A}$ was used to generate pSB42 and pSB249.

Plasmids expressing $\mathrm{N}$ - or C-terminally truncated Sap1p propeptide were constructed after PCR amplification of pSB42 fragments with appropriate homologous primers. The PCR products were used to replace the corresponding part encoding the full-length propeptide in pSB42. Subsequently, plasmids expressing Sap1p propeptide truncated at both extremities were constructed in a similar way using previously constructed plasmids encoding Sap1p propeptide truncated at one extremity (see Fig. 4). Plasmids expressing other Sap propeptides were constructed as pSB42 using different SAP DNA as a template (Togni et al., 1991; de Viragh et al., 1993; Monod et al., 1994). All cloned fragments were further sequenced to confirm the absence of possible PCR induced errors.

In vitro mutagenesis. For construction of pSB269, the following pairs of sense and antisense primers were used to amplify two contiguous fragments of pSB10: TTGGAGCTCGCTCATTCCAAT and AGTGACGTCACCTGGGGATCTTTTAGCTGG; GGTGACGTCACTTTAGACTTTGATGTC and TTAGCGGCCGCTCTAGGTAAGAGCAGCAATGTT. Subsequently, the $0.8 \mathrm{~kb}$ SacI-NotI fragment of pKJ113 was excised and replaced by adding end-to-end the two PCR products digested by SacI/AatII and AatII/NotI.

P. pastoris transformation. P. pastoris was transformed by electroporation with 5-10 $\mu$ g linearized plasmid DNA digested by SmaI using pKJ113 constructs, and SacI or BstXI using pPICZ $\alpha$ A constructs. The $\mathrm{His}^{-} \mathrm{Mut}^{+} \mathrm{P}$. pastoris strain GS115 was transformed with pKJ113 constructs, and transformants 
were selected on histidine-deficient medium [1 $\mathrm{M}$ sorbitol, $1 \%$ $(\mathrm{w} / \mathrm{v})$ glucose, $1.34 \%(\mathrm{w} / \mathrm{v})$ yeast nitrogen base $(\mathrm{YNB})$ without amino acids, $4 \times 10^{-5} \%(\mathrm{w} / \mathrm{v})$ biotin, amino acids $(0.005 \%, w / v$, each of L-glutamic acid, L-methionine, Llysine, $\mathrm{L}$-leucine and L-isoleucine), $2 \%(\mathrm{w} / \mathrm{v})$ agarose]. Subsequently, the tranformants were screened for insertion of the construct at the $A O X 1$ site on minimal methanol plates $\left[1.34 \%(\mathrm{w} / \mathrm{v})\right.$ YNB without amino acids, $4 \times 10^{-5} \%(\mathrm{w} / \mathrm{v})$ biotin, $0.5 \%(\mathrm{v} / \mathrm{v})$ methanol, $2 \%(\mathrm{w} / \mathrm{v})$ agarose]. Transformants unable to grow on media containing only methanol as a carbon source were retained for further investigations. They were assumed to contain the construct at the correct yeast genomic location by integration events in the AOX1 locus displacing the $A O X 1$ coding region. The prototrophic $P$. pastoris strains were transformed with pPICZ $\alpha \mathrm{A}$ constructs and transformants were selected on YPDS medium containing $100 \mu \mathrm{g}$ zeocin $\mathrm{ml}^{-1}$ (Invitrogen).

Production of Sap1p in $\boldsymbol{P}$. pastoris. All selected transformants were grown to near saturation $\left(\mathrm{OD}_{600} 10\right)$ at $30^{\circ} \mathrm{C}$ in $10 \mathrm{ml}$ glycerol-based yeast medium $[0 \cdot 1 \mathrm{M}$ potassium phosphate buffer $\mathrm{pH} 6 \cdot 0$, containing $1 \%(\mathrm{w} / \mathrm{v})$ yeast extract, $2 \%(\mathrm{w} / \mathrm{v})$ peptone, $1.34 \%(\mathrm{w} / \mathrm{v})$ YNB without amino acids, $1 \%(\mathrm{v} / \mathrm{v})$ glycerol and $4 \times 10^{-5} \%$ (w/v) biotin]. Cells were harvested by centrifugation and resuspended in $2 \mathrm{ml}$ of the same medium with $0.5 \%(\mathrm{v} / \mathrm{v})$ methanol instead of glycerol and incubated for $2 \mathrm{~d}$. Thereafter, the supernatants and the cell pellets were separated by centrifugation and retained for protein analysis.

Protein extract analysis. The proteins in 5 or $10 \mu \mathrm{l}$ of $P$. pastoris culture supernatant were loaded without further treatment onto SDS-PAGE gels (Laemmli, 1970). Cell protein extracts of $0.1 \mathrm{ml}$ culture were prepared following the method of Yaffe \& Schatz (1984). The pelleted cells were resuspended in $200 \mu 11.8 \mathrm{M} \mathrm{NaOH}, 1.2 \mathrm{M} \beta$-mercaptoethanol, and incubated for $5 \mathrm{~min}$ on ice. After addition of $200 \mu \mathrm{l} 10 \%$ TCA, the mixture was incubated for $5 \mathrm{~min}$, centrifuged, and the pellet was resuspended in $50 \mu \mathrm{l} 2 \times$ SDS-PAGE loading buffer and neutralized at $\mathrm{pH} 7 \cdot 0$ by adding $5-10 \mu \mathrm{l} 1 \mathrm{M}$ Tris base. The samples were heated to $95^{\circ} \mathrm{C}$ for $3 \mathrm{~min}$ before loading onto SDS-PAGE gels ( $12 \%$ acrylamide).

Untagged Sap1p was separated from $\mathrm{His}_{6}$-tagged Sap1p $\left(\mathrm{H}_{6}{ }^{-}\right.$ Sap1p) by filtration of the $P$. pastoris culture supernatant through a nickel chelating resin column (ProBond, Invitrogen) equilibrated with $10 \mathrm{mM}$ phosphate buffer, $\mathrm{pH} 7 \cdot 0$. After washing the column with the same buffer, adsorbed $\mathrm{H}_{6}$-Sap1p was eluted with $300 \mathrm{mM}$ imidazole buffer, pH 6.0. All fractions with detectable enzymic activity were retained and pooled. Sap1p was purified from filtered P. pastoris culture supernatant as previously described (Borg-von Zepelin et al., 1998). Protein concentrations were measured by the method of Bradford (1976).

SDS-PAGE gels were stained with Coomassie brilliant blue R250 (Bio-Rad). Immunodevelopment of Western blots was performed using an antiserum $(\alpha$-Sap 2$)$ raised in rabbits and cross-reacting with Sap1p (Borg-von Zepelin et al., 1998), and alkaline-phosphatase-conjugated goat anti-rabbit IgG (Bio$\mathrm{Rad}$ ), or using an anti-polyhistidine peroxidase conjugate monoclonal antibody (Sigma).

Proteolytic assays. The proteolytic activity of Sap isoenzymes was measured with $0.02 \%(\mathrm{w} / \mathrm{v})$ resorufin-labelled casein as a substrate (Roche Diagnostics) in sodium citrate buffer $(50 \mathrm{mM}$; $\mathrm{pH} 4.5)$ in a total volume of $0.25 \mathrm{ml}$. After incubation at $37^{\circ} \mathrm{C}$ for $60 \mathrm{~min}$, the undigested substrate was precipitated by TCA acid ( $5 \%$ final concentration) and separated from the supernatant by centrifugation. The absorbance of the super- natant was measured in the alkaline range at $574 \mathrm{~nm}$ after adding $250 \mu \mathrm{l} 1 \mathrm{M}$ Tris $/ \mathrm{HCl}$ at $\mathrm{pH} 10$. For practical purposes, one unit of Sap1p activity was defined as that producing an absorbance of 0.001 per min.

\section{RESULTS}

\section{Importance of the propeptide for secretion of recombinant Sap1p by $P$. pastoris}

In a preliminary experiment, $P$. pastoris was used to express the gene SAP1 with and without the nucleotide sequence encoding the propeptide. SAP1 DNA fragments (bp 59-1176 and bp 152-1176 of the open reading frame) were cloned into pKJ113 downstream of the PHO1 signal peptide sequence, generating the plasmids pSB10 and pSB11, respectively (Table 1). Plasmid pKJ113 is a low-copy-number E. coli vector which contains the $P$. pastoris pHIL-S1 expression cassette. The pHIL-S1 constructs insert into the $P$. pastoris genome via homologous recombination at the $A O X 1$ site and carry, in addition to the cloned coding sequence of interest, the HIS4 gene for selection after transformation of $P$. pastoris GS115 with linearized plasmidic DNA. The resulting $\mathrm{His}^{+} \mathrm{Mut}^{-}$transformants were selected and screened for proteinase production. C. albicans Sap1p was recovered as a single protein and an active enzyme in the $P$. pastoris culture supernatants in all transformants with a yield of approximately $350 \mathrm{U}$ $\mathrm{ml}^{-1}\left(50 \mu \mathrm{g} \mathrm{ml}^{-1}\right)$ when its encoding nucleotide sequence was expressed behind that of its propeptide. Direct expression of the SAP1 gene without its propeptide did not lead to secretion of recombinant protein into the culture supernatant of $P$. pastoris transformants. An accumulation of Sap1p in the cell was demonstrated by Western blotting of total protein extracts immunodeveloped with anti-Sap antibody (Fig. 1). One strain secreting and one strain accumulating Sap1p were selected, and labelled SB10 and SB11, respectively, in subsequent investigations (Table 1 ).

\section{Rescue of Sap1p secretion by unlinked propeptides}

The nucleotide sequence encoding the Sap1p propeptide was cloned into plasmid pPICZ $\alpha \mathrm{A}$ downstream from the $\alpha$-factor signal peptide sequence generating the plasmid pSB42 (Table 2). This construction was performed in order to provide an access into the secretory pathway for the propeptide as a separate protein. $P$. pastoris SB11, which does not secrete Sap1p, was transformed with linearized pSB42 DNA, and clones resistant to zeocin were further tested for proteinase production. C. albicans Sap1p was recovered as a single protein and an active enzyme in all transformant culture supernatants with a yield comparable to that of strain SB10. Therefore, co-expression in P. pastoris of a noncovalently attached propeptide could rescue the lack of cis-expressed propeptide.

Five transformants were retained for restriction fragment analysis. Genomic DNA of the yeasts was digested with SacI, DraI and HindIII, electrophoresed and probed 
Table 1. P. pastoris GS115 and KM71 transformants generated in this study

The SAP1 translation products produced with a full length propeptide, without propeptide, with a non-functional propeptide (F27 $\rightarrow \mathrm{D}$ mutation) and with a C-terminal $\mathrm{His}_{6}$ tag are abbreviated as Pre-Pro-Mat, Pre-Mat, Pre-Pro*-Mat and Pre-Pro-Mat- $\mathrm{H}_{6}$, respectively.

\begin{tabular}{|lcllc|}
\hline Strain & $\begin{array}{c}\text { Transformed } \\
\text { original } \\
\text { strain }\end{array}$ & Plasmid & $\begin{array}{c}\text { SAP1 translation } \\
\text { product }\end{array}$ & $\begin{array}{c}\text { Secreted proteolytic } \\
\text { activity }\left(\mathbf{U ~ m l}^{-1}\right)\end{array}$ \\
\hline SB10 & GS115 & pSB10 & Pre-Pro-Mat & 352 \\
SB11 & GS115 & pSB11 & Pre-Mat & 0 \\
SB269 & GS115 & pSB269 & Pre-Pro*-Mat & 0 \\
SB249 & KM71 & pSB249 & Pre-Pro-Mat-H & 324 \\
\hline
\end{tabular}

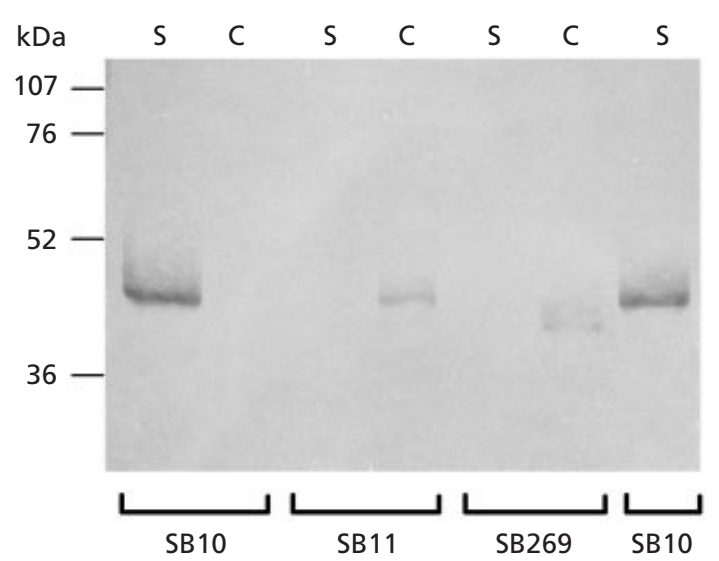

Fig. 1. Detection of Sap $1 \mathrm{p}$ from $P$. pastoris $\mathrm{SB} 10, \mathrm{SB} 11$ and SB269. The proteins in $5 \mu$ l of supernatant (S) without further treatment and in cell extracts (C) from $5 \mu \mathrm{l}$ of methanolinduced culture were separated by SDS-PAGE and analysed by Western blotting.

with the larger BamHI-BglII fragment of plasmid pPICZ $\alpha$ A containing the Streptoalloteichus hindustanus $B L E$ gene for resistance to zeocin (Gatignol et al.,
1988; Drocourt et al., 1990) (Fig. 2). The band pattern of transformants secreting Sap1p, which showed a hybridizing fragment of identical size $(3 \cdot 8 \mathrm{~kb})$ for each of the restriction digests, was consistent with the correct integration of $\mathrm{pPICZ} \alpha \mathrm{A}$ contructs at the locus of the AOX1 promoter of the SB11 strain (data not shown). In our genetic construction, DNA encoding Sap1p propeptide and DNA encoding Sap1p without its propeptide are in tandem under the control of $p A O X 1$ (Fig. 2).

In a similar experiment, we tested whether the secretion defect of Sap1p in P. pastoris SB11 could also be rescued by providing other secreted proteinase propeptides as a separate protein (Table 2, Fig. 3). Sap1p was recovered as a single protein and an active enzyme in the $P$. pastoris culture supernatants with a yield varying from 128 to 320 units, corresponding to 16 to $40 \mu \mathrm{g} \mathrm{ml}^{-1}$, using all Sap propeptides tested. The specific activities of the Sap1p enzymes secreted by the different strains were the same.

Using pSB42, we constructed a series of plasmids encoding the Sap1p propeptide deleted at the N- or the C-terminus, or both (Fig. 4) in order to determine the

Table 2. Sap propeptides used as a separate protein to rescue Sap1p secretion in strain SB11, and Sap1p activity of SB11 transformants

\begin{tabular}{|c|c|c|}
\hline Plasmid (encoded propeptide) & Sap propeptide aa sequence & $\begin{array}{c}\text { Saplp activity } \\
\text { of SB11 } \\
\text { transformants }(\%)^{*}\end{array}$ \\
\hline \multicolumn{3}{|c|}{$\downarrow$} \\
\hline pSB42 (Sap1p propeptide) & $\ldots \ldots$ SPAKR . SPGGVTILDFDVIKT $\ldots \ldots \ldots \ldots \ldots \ldots \ldots \ldots$ PVNATGQEGKV. KR & 100 \\
\hline pSB104 (Sap2p propeptide) & $\ldots \ldots$ TPTTTLR. SAGFVALDFSVVKT $\ldots \ldots \ldots \ldots \ldots \ldots$ PKAFPVTNGQEGKTS.$\underline{\underline{K R}}$ & $82 \pm 4$ \\
\hline pSB105 (Sap3p propeptide) & $\ldots \ldots$ TPTTFNN. SP GFVALNEDVIKT $\ldots \ldots \ldots \ldots \ldots \ldots$ HKNVTGPQGEINTNVNV. $\underline{\underline{K R}}$ & $61 \pm 5$ \\
\hline pSB106 (Sap6p propeptide) & 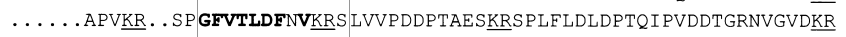 & $78 \pm 4$ \\
\hline pSB107 (Sapp2p propeptide) & GAAIPD. PAKRDDNP GFVALDFEVTRK $\ldots \ldots \ldots \ldots \ldots \ldots \ldots$ PLDVNATSELS.$\overline{\mathrm{KR}}$ & $40 \pm 1$ \\
\hline pSB108 (Sapt1p propeptide) & 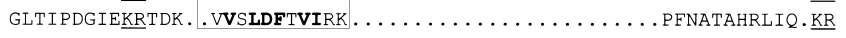 & $44 \pm 4$ \\
\hline
\end{tabular}

* The percentage values refer to the activity of SB11 transformed with pSB42 encoding the Sap1p propeptide. The value of $100 \%$ corresponds to $320 \mathrm{U} \mathrm{ml}^{-1}$. The values shown are mean activities with standard deviation obtained from three experiments. No proteolytic activity was detected in SB11 culture supernatant.

The arrow indicates the F residue substituted by a D in strain SB269. 


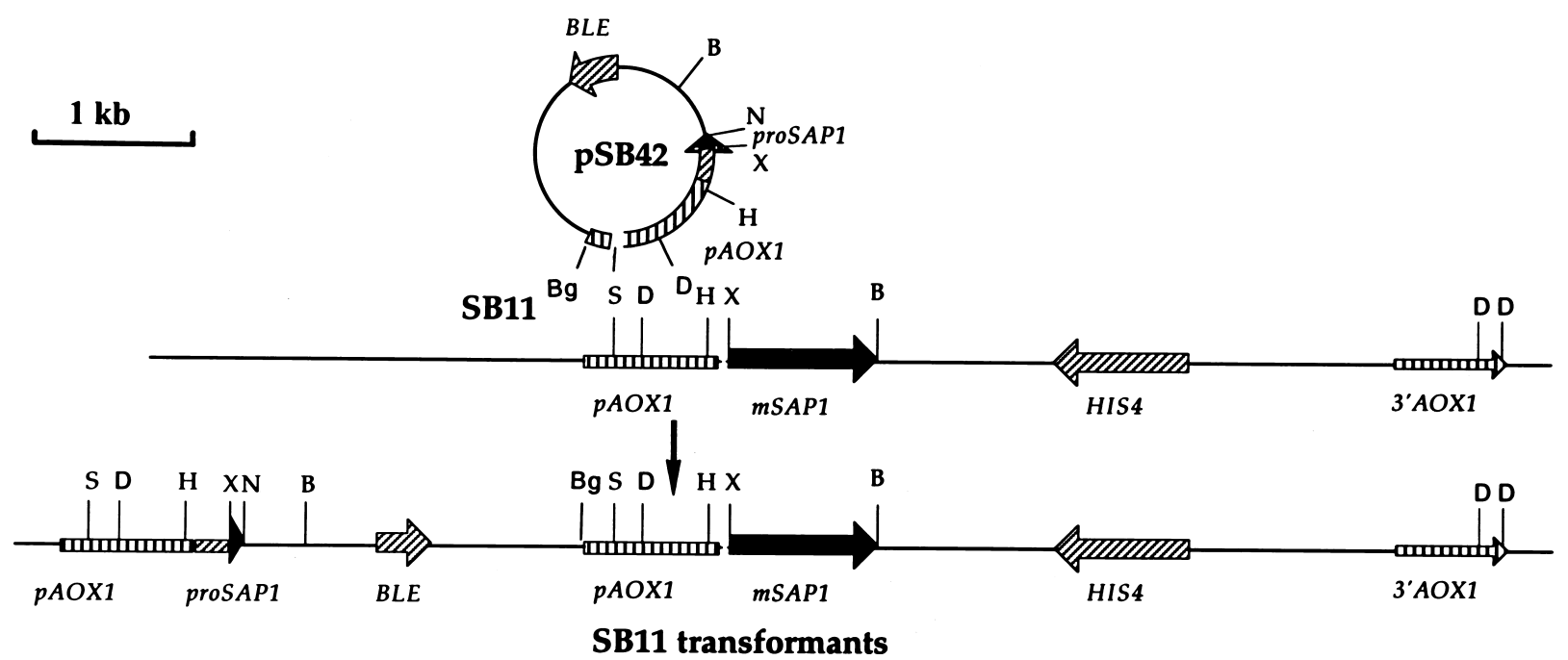

Fig. 2. Chromosomal integration of $\mathrm{pSB} 42$ in SB11 transformants. $p A O X 1, P$. pastoris alcohol oxidase gene (AOX1) promoter; proSAP1, part of SAP1 encoding the Sap1p propeptide; mSAP1, part of SAP1 encoding the mature part of Sap1p; BLE, S. hindustanus BLE gene for resistance to zeocin; HIS4, P. pastoris histidinol dehydrogenase gene; 3'AOX1, 3'AOX1 downstream sequence; B, BamHI; Bg, Bg/lI, D, Dral; H, HindlII; N, Notl; S, Sacl; X, Xhol.

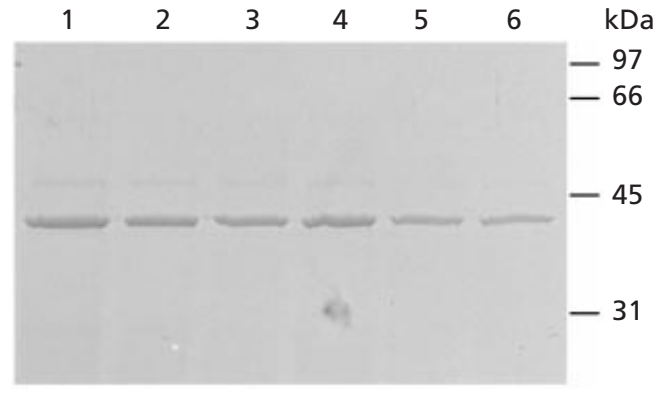

Fig. 3. Detection of Sap1p in culture supernatants of $S B 11$ transformants co-producing propeptides encoded by the plasmids pSB42 (lane 1), pSB104 (lane 2), pSB105 (lane 3), pSB106 (lane 4), pSB107 (lane 5) and pSB108 (lane 6). The different propeptides encoded by these plasmids are reported in Table 2. The proteins in $10 \mu$ l supernatant without further treatment were separated by SDS-PAGE and stained with Coomassie blue. $\mathrm{M}$, molecular mass markers.

active part necessary for maturation and secretion of the enzyme. All SB11 transformants producing a peptide containing the 12 aa sequence GFVTLDFDVIKT secreted $80-100 \%$ of Sap1p activity in comparison to the action of the entire propeptide. Removing the $\mathrm{G}$ residue from the $\mathrm{N}$-terminus or the $\mathrm{T}$ residue from the $\mathrm{C}$ terminus of this 12 aa sequence reduced the amount of secreted activity by approximately one-third and onehalf, respectively. Removing 2 or 3 aa from the $\mathrm{N}$ terminus or from the C-terminus, respectively, prevented Sap1p secretion.

\section{Maturation of Sap1p molecules in an intermolecular process}

Following the results of the propeptide deletion analysis, a mutation was introduced in plasmid pSB10 to replace the phenylalanine $(\mathrm{F})$ residue 27 of the SAP1 translation product, which is conserved in different Sap propeptides (Table 2), by an aspartic acid (D) residue. The newly generated plasmid was called pSB269 (Table 1). Direct expression of the mutated SAP1 gene in P. pastoris GS115 did not result in the secretion of Sap1p into the culture supernatant. However, a Sap1p product with an electrophoretic mobility higher than that of the mature form of Sap1p was detected in all transformants, from among which strain SB269 was selected (Table 1, Fig. 1).

The question whether the maturation of Sap1p occurs in vivo through inter- or intramolecular events was investigated by attempting to rescue the secretion of the enzyme produced in SB11 without propeptide, or in SB269 with a mutated non-functional propeptide, by a co-production of Sap1p with non-mutated propeptide. For such an experiment, a DNA fragment encoding Sap1p with a non-mutated prosequence and with a Cterminal $\mathrm{His}_{6}$-tag was cloned into pPICZ $\alpha \mathrm{A}$. P. pastoris KM71 transformed with the newly generated plasmid pSB249 produced $\mathrm{His}_{6}$-tagged Sap1p $\left(\mathrm{H}_{6}\right.$-Sap1p; Fig. 5, lane 1) with a yield comparable to that of Sap1p produced by strain SB10 (Table 1). The specific activity of purified $\mathrm{H}_{6}$-Sap1p was equal to that of Sap1p (9.5 U $\mu \mathrm{g}^{-1}$ ). When SB10 was transformed by pSB249, both Sap1p and $\mathrm{H}_{6}$-Sap1p were found, in a ratio close to $1: 1$ $(90: 100)$, in culture supernatant of all transformants (Fig. 5, lane 10). The total secreted proteolytic activity of 


\begin{tabular}{|c|c|}
\hline Propeptide & $\underline{\text { Sap1p activity (\%) }}$ \\
\hline SPAKRSPGGFTLDFDVIKTPVNATGQEGKVKR & 100 \\
\hline 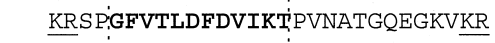 & $97 \pm 4$ \\
\hline PGFVTLDFDVIKTPVNATGQEGKVKR & $94 \pm 7$ \\
\hline GFVTLDFDVIKTPVNATGQEGKVKR & $84 \pm 6$ \\
\hline FVTLDFDVIKTPVNATGQEGKVKR & $57 \pm 1$ \\
\hline VTLDFDVIKTiPVNATGQEGKVKR & 0 \\
\hline SPAKRSPGFVTLDFDVIKTPVNATGQ & $98 \pm 5$ \\
\hline SPAKRSP'GFVTLDFDVIKT'PVN & $100 \pm 8$ \\
\hline SPAKRSPGFVTLDFDVIKT:PV & $99 \pm 5$ \\
\hline SPAKRSPGFVTLDFDVIKTP & $84 \pm 7$ \\
\hline SPAKRSPGGVTLDFDVIKT' & $80 \pm 10$ \\
\hline SPAKRSPGGFTLDFDVIK & $67 \pm 1$ \\
\hline SPAKRSPGFVTLDFDVI & $28 \pm 3$ \\
\hline SPAKRSP:GFVTLDFDV & 0 \\
\hline SPAKRSP'GFVTLDFD & 0 \\
\hline GFVTLDFDVIKTPVN & $98 \pm 7$ \\
\hline GFVTLDFDVIKTPV & $94 \pm 5$ \\
\hline GFVTLDFDVIKT:P & $80 \pm 3$ \\
\hline GFVTLDFDVIKT & $84 \pm 9$ \\
\hline GFVTLDFDVIK & $37 \pm 3$ \\
\hline GFVTLDFDVI & $19 \pm 1$ \\
\hline FVTLDFDVIKT:PVN & $71 \pm 4$ \\
\hline FVTLDFDVIKTุ'PV & $63 \pm 4$ \\
\hline FVTLDFDVIKTP & $46 \pm 1$ \\
\hline FVTLDFDVIKT & $38 \pm 11$ \\
\hline FVTLDFDVIK & $24 \pm 5$ \\
\hline 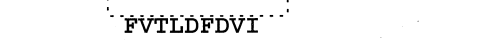 & $10 \pm 1$ \\
\hline
\end{tabular}

Fig. 4. $\mathrm{N}$ - and/or C-terminally truncated Sap $1 \mathrm{p}$ propeptides encoded by pSB42 derivatives, and Sap1p activity of SB11 transformants. The first line shows the full-length Sap1p propeptide encoded by pSB42. The Sap1p activity of SB11 transformed with pSB42 $\left(320 \mathrm{U} \mathrm{ml}^{-1}\right)$ was set to $100 \%$. The values shown are the mean activity with standard deviation obtained from three experiments.

SB10 transformants was twice that of the SB10 strain. Untagged Sap1p could be separated from $\mathrm{H}_{6}-\mathrm{Sap} 1 \mathrm{p}$ by filtration of the $P$. pastoris culture supernatant through a nickel chelating resin column (Fig. 5, lanes 11 and 12). No $\mathrm{H}_{6}$-Sap1p was detected in the culture supernatant after filtration through the column (Fig. 5, lane 12). Adsorbed $\mathrm{H}_{6}$-Sap1p could be subsequently released with imidazole for quantification.

When $P$. pastoris SB11 producing Sap1p without propeptide and SB269 producing Sap1p with a mutated propeptide were transformed by plasmid pSB249, Sap1p and $\mathrm{H}_{6}-\mathrm{Sap} 1 \mathrm{p}$ were again both secreted in the culture supernatants of all transformants, but in a ratio close to 1:2 (54:100) (Fig. 5, lanes 4-9) Therefore, $\mathrm{H}_{6}$-Sap1p encoded by pSB249 permitted a restoration of secretion of Sap1p made without propeptide and with a mutated propeptide in the SB11 and SB269 transformants, (a)

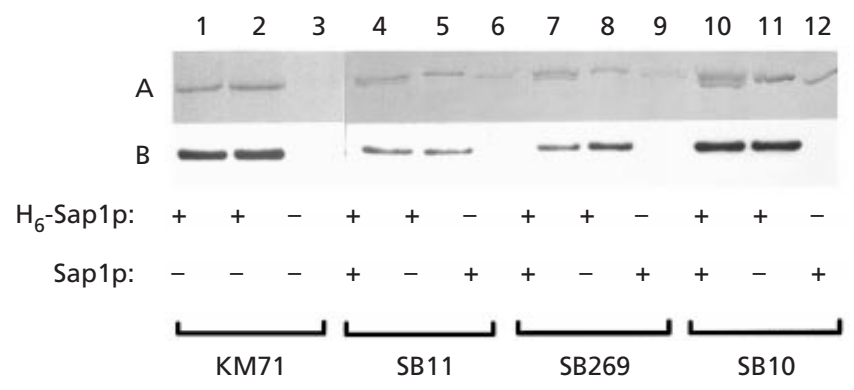

(b)

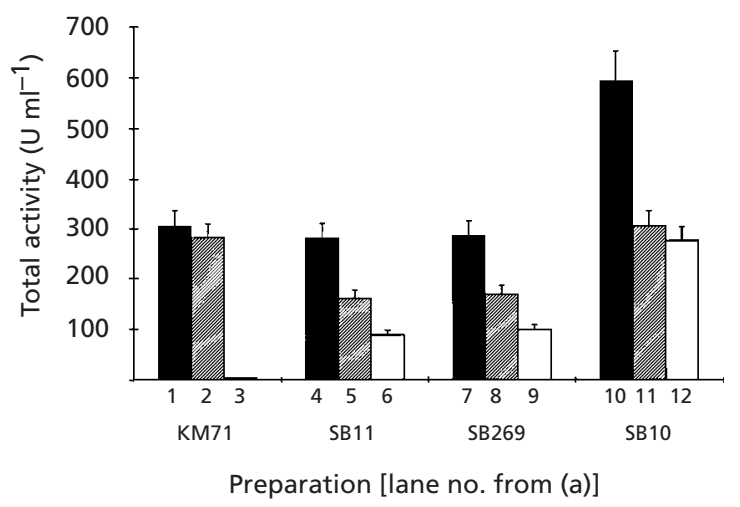

Fig. 5. (a) Protein preparations from the culture supernatants of $P$. pastoris KM71, SB11, SB269 and SB10 transformed with pSB249. A $5 \mathrm{ml}$ sample of $P$. pastoris culture supernatant was filtered through a $1.0 \mathrm{ml}$ nickel chelating resin column as described in Methods. After washing of the column, the adsorbed $\mathrm{H}_{6}$-Sap1 $\mathrm{p}$ was eluted with imidazole buffer. All fractions with detectable enzymic activity were retained and pooled and the volume was adjusted to $5.0 \mathrm{ml}$ for comparison with the culture supernatant filtrate. Lanes 1, 4, 7, 10: culture supernatant loaded without further treatment. Lanes 2, 5, 8, 11: $\mathrm{H}_{6}$-Sap1p eluted from the nickel column. Lanes $3,6,9,12$ : Sap1p in the culture supernatant after filtation through the column. Ten microlitres of each preparation was analysed by SDS-PAGE. A, gel stained with Coomassie brillant blue; B, immunodetection of Sap1p using anti-polyhistidine monoclonal antibody. Only $\mathrm{H}_{6}$-Sap1p was detected. (b) Total activities of each preparation.

respectively. However, this restoration occurred at the expense of secretion of $\mathrm{H}_{6}$-Sap1p since the proteolytic activity of SB11 and SB269 transformants was similar to that of $P$. pastoris KM71 transformed with pSB249, but not higher. Furthermore, an accumulation of $\mathrm{H}_{6}$-Sap1p product with an electrophoretic mobility higher than that of Sap1p was observed in cell extracts of SB11 and SB269 transformants but not in those of KM71 and SB10 transformants (Fig. 6).

\section{DISCUSSION}

When not covalently attached to the mature domain, only a 12 aa segment of the propeptide was necessary and sufficient to ensure complete Sap1p secretion. The 
(a)

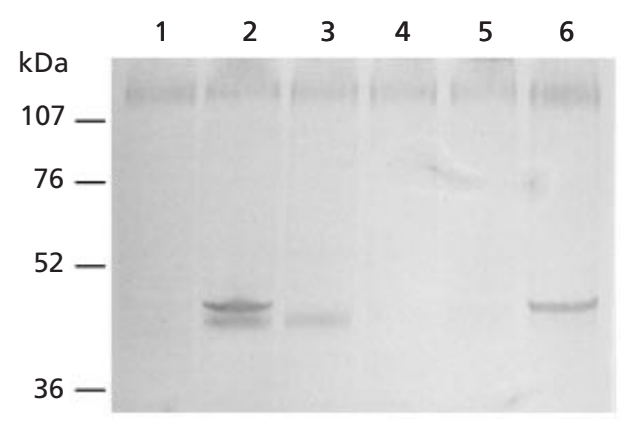

(b)

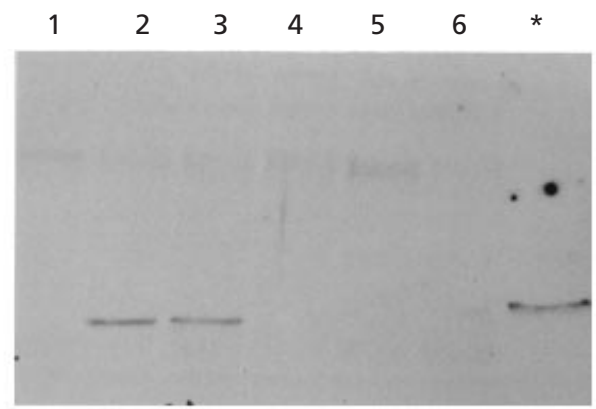

Fig. 6. Detection of Sap1p and $\mathrm{H}_{6}$-Sap1p intracellular products from strains KM71 (1), SB11 (2), SB269 (3) and SB10 (4) transformed with pSB249. The proteins in cell extracts from $5 \mu$ of methanol-induced culture were separated by SDSPAGE and analysed by Western blotting using anti-Sap polyclonal antibody (a) and anti-polyhistidine monoclonal antibody (b). Cell extracts of SB10 (5) and SB11 (6) strains and $5 \mu$ l of SB249 culture supernatant (*) were added on the gels for comparison of molecular masses of Sap1p products.

amino acid sequences of the Candida Saps show considerable homology to each other and this 12 aa segment corresponds to a highly conserved region in all Sap propeptides (Table 2). Consistently, the secretion defect of Sap1p in P. pastoris SB11 could be rescued by other Sap propeptides expressed as separate proteins, albeit with reduced efficiency when the propeptides had reduced homology. The activity detected in the culture supernatant was proportional to the amount of secreted protein (Fig. 3). We conclude that all Sap1p molecules in the culture supernatants were enzymically active. In another set of experiments, we found that the 12 aa homologous sequence in the Sap6p propeptide was also sufficient for the maturation of Sap6p (unpublished data). The requirement for only a short segment of the propeptide appears to be a characteristic of Sap enzymes. In contrast, a relatively long domain in the propeptide is essential for assisting the correct folding and the secretion of the mature bacterial subtilisins, since prosubtilisin molecules with unique point mutations distributed throughout the whole propeptide (in positions -76 to -13 ) did not yield active subtilisin (Lerner et al., 1990; Inouye, 1991).

The fate of eukaryotic proproteinases mutated in their prosequence was previously investigated with the Yarrowia lipolytica alkaline proteinase and the Rhizopus niveus aspartic proteinase I (Fabre et al., 1991; Fukuda et al., 1996). All deletions affecting the proregion of the Y. lipolitica alkaline proteinase precursor resulted in the intracellular accumulation of unprocessed protein. The rates of synthesis of one mutated and one prodeleted precursor of the $R$. niveus aspartic proteinase I were comparable in Saccharomyces cerevisiae, but both precursors were degraded in the endoplasmic reticulum. As a general rule, misfolded or unfolded proteins are selectively retained in the endoplasmic reticulum (Helenius et al., 1992), where a more or less rapid degradation occurs depending on the protein. The amount of Sap1p product detected intracellularly when Sap1p was produced with a mutated propeptide or without a propeptide was reduced, which suggests protein degradation (Fig. 1). It is likely that the nonfunctional folding of Sap1p results in the degradation of its mature domain, which consequently causes the lack of secretion of the Sap1p molecules. When SAP1 was expressed without its propeptide sequence an accumulation of Sap1p product with the same electrophoretic mobility as secreted Sap1p was observed in the cell. In contrast, an accumulation of a Sap1p product with an electophoretic mobility higher than Sap1p was observed when SAP1 was expressed with a sequence encoding a mutated propeptide (Fig. 1). A similar $\mathrm{His}_{6}$-tagged product was detected in cell extracts of pSB249 transformants of SB11 and SB269 in parallel with the rescue of Sap1p secretion (Fig. 6, lanes 2 and 3). It appears that Sap1p produced without a propeptide and Sap1p produced with a mutated propeptide are not degraded in the same way.

The proteolytic activity of the SB11 and SB269 transformants secreting two Sap1ps produced with and without a functional propeptide under the control of two identical promoters was similar to that of KM71 transformed with pSB249 (Fig. 5). The lack of increased proteolytic activity in these transformants producing two different proteins can only be explained by a singleturnover catalytic property of the propeptide, meaning that each propeptide only participates in a single proteinfolding reaction (Ohta et al., 1991; Baker et al., 1992).

If folding of the Sap1p molecules were obligatorily assisted by their propeptide in cis (first-order reaction, Fig. 7a), only $\mathrm{H}_{6}$-Sap1p would have been secreted by the SB11 and SB269 transformants. Therefore, as our experiments demonstrate, there must be an intermolecular pathway to mature Sap1p without a priori exclusion of a possible intramolecular one. It was previously shown that prosubtilisin exists as dimers under non-denaturing conditions in vitro ( $\mathrm{Hu}$ et al., 1996). A model of enzyme maturation was postulated where the prosequence of one prosubtilisin molecule is 
(a)

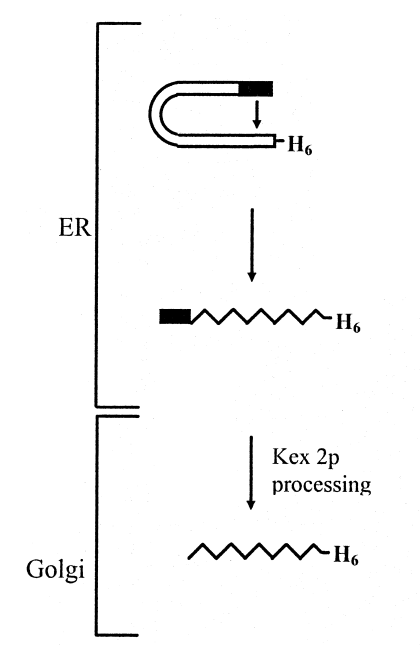

(b)
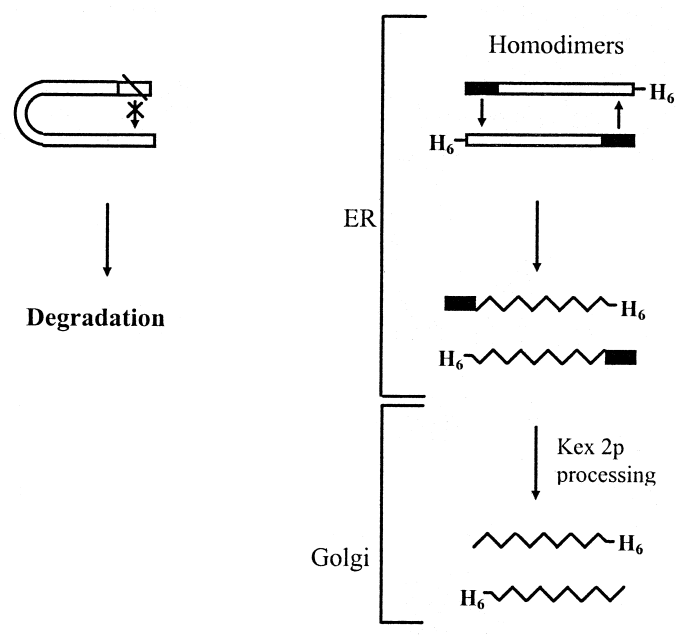

Degradation

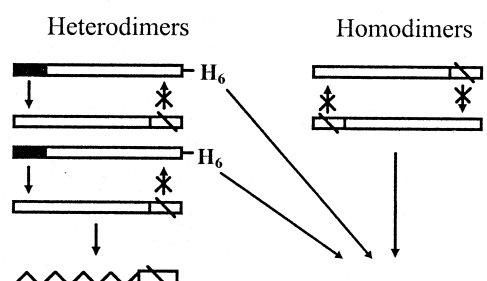

Degradation

Fig. 7. Model for intra- and intermolecular events in Sap1P maturation in P. pastoris SB269 transformed with pSB249. The $F 27 \rightarrow D$ mutation in the Sap1p propeptide is indicated by an oblique line across the propeptide. (a) First-order reaction. The folding of an enzyme molecule is guided by its own propeptide. Using such a mechanism, only $\mathrm{H}_{6}$-Sap $1 \mathrm{p}$ is matured. (b) Second-order reaction. Assuming that Sap1p and $\mathrm{H}_{6}$-Sap1p are synthesized in a ratio of $1: 1$, intracellular Sap1p homodimer-, Sap1p/ $\mathrm{H}_{6}$-Sap1p heterodimer- and $\mathrm{H}_{6}$-Sap1p homodimer-formations should occur in a 1:2:1 ratio. In this model, the homodimers made of $\mathrm{H}_{6}$-Sap1 $\mathrm{p}$ with an active propeptide generate two molecules of secreted active enzyme. The homodimers made of Sap1p with a mutated and non-functional propeptide generate no active enzyme, while heterodimers generate one molecule of Sap1p. Therefore, a strict intermolecular mechanism would predict a ratio of $\mathrm{H}_{6}$ Sap1p to Sap1p of 1:1 in the culture supernatant.

the template for the refolding of the mature sequence of the second one (second-order reaction). A strict intermolecular mechanism would predict a ratio of $\mathrm{H}_{6}-\mathrm{Sap} 1 \mathrm{p}$ to Sap1p of 1:1 in the culture supernatant of SB11 and SB269 transformants assuming that Sap1p and $\mathrm{H}_{6}-\mathrm{Sap} 1 \mathrm{p}$ are synthesized in a ratio of $1: 1$ (Fig. $7 \mathrm{~b}$ ). In fact, the ratio of $\mathrm{H}_{6}$-Sap1p to Sap1p was experimentally determined to be close to $2: 1$. This result leads to the conclusion that maturation of Sap1p occurs in $P$. pastoris through both intra- and intermolecular pathways (Fig. 7). The observation of an intracellular accumulation of a $\mathrm{H}_{6}$-Sap1p product in the SB11 and SB269 transformants (Fig. 6) is consistent with the prediction that $\mathrm{H}_{6}$-Sap1p molecules do not mature without a propeptide or with a non-functional propeptide in heterodimers (Fig. 7).

This is the first report demonstrating that the maturation of an enzyme in vivo can be guided by the propeptide in an intermolecular process. The strategy developed in this work for Sap1p secretion could be used to test whether maturation of other proteinases via a combination of intra- and intermolecular pathways is a general pattern.

\section{ACKNOWLEDGEMENTS}

S. Beggah performed this work in partial fulfilment of the requirements for a $\mathrm{PhD}$ degree from the University of Lausanne (Switzerland). We thank J. Wyniger and C. Zaugg for technical assistance, and Dr M. Holdom, Dr H. Pooley, Dr E. Grouzmann and Dr D. Sanglard for critical review of the manuscript and assistance with the English. This work was supported by the Swiss National Foundation for Scientific Research, grant 3100-043193.

\section{REFERENCES}

Baker, D., Sohl, J. L. \& Agard, D. A. (1992). A protein-folding reaction under kinetic control. Nature 356, 263-265.

Borg-von Zepelin, M., Beggah, S., Boggian, K., Sanglard, D. \& Monod, M. (1998). The expression of the secreted aspartyl proteinases Sap4 to Sap6 from Candida albicans in murine macrophages. Mol Microbiol 28, 543-554.

Bradford, M. M. (1976). A rapid and sensitive method for the quantitation of microgram quantities of protein utilizing the principle of protein-dye binding. Anal Biochem 72, 248-254.

Drocourt, D., Calmels, T. P. G., Reynes, J. P., Baron, M. \& Tiraby, G. (1990). Casettes of the Streptoalloteichus hindustanus ble gene for transformation of lower and higher eucaryotes to phleomycine resistance. Nucleic Acids Res 18, 4009.

Eder, J. \& Fersht, A. R. (1995). Pro-sequence-assisted protein folding. Mol Microbiol 16, 609-614.

Fabre, E., Nicaud, J. M., Lopez, M. C. \& Gaillardin, C. (1991). Role of the proregion in the production and secretion of the Yarrowia lipolytica alkaline extracellular protease. J Biol Chem 266, 3782-3790.

Fabre, E., Tharaud, C. \& Gaillardin, C. (1992). Intracellular transit of a yeast protease is rescued by trans-complementation with its prodomain. J Biol Chem 267, 15049-15055.

Fallon, K., Bausch, K., Noonan, J., Huguenel, E. \& Tamburini, P. (1997). Role of aspartic proteases in disseminated Candida albicans infection in mice. Infect Immun 65, 551-556.

Fukuda, R., Horiuchi, H., Ohta, A. \& Takagi, M. (1994). The prosequence of Rhizopus niveus aspartic proteinase-I supports 
correct folding and secretion of its mature part in Saccharomyces cerevisiae. J Biol Chem 269, 9556-9561.

Fukuda, R., Umebayashi, K., Horiuchi, H., Ohta, A. \& Takagi, M. (1996). Degradation of Rhizopus niveus aspartic proteinase-I with mutated prosequences occurs in the endoplasmic reticulum of Saccharomyces cerevisiae. J Biol Chem 271, 14252-14255.

Gatignol, A., Durand, H. \& Tiraby, G. (1988). Bleomycin resistance conferred by a drug-binding protein. FEBS Lett 230, 171-175.

van den Hazel, H., Kielland-Brandt, M. C. \& Winther, J. R. (1994). The propeptide is required for in vivo formation of stable active yeast proteinase $\mathrm{A}$ and can function even when not covalently linked to the mature region. J Biol Chem 268, 18002-18007.

Helenius, A., Marquart, T. \& Braakman, I. (1992). The endoplasmic reticulum as a protein-folding compartment. Trends Cell Biol 2, 227-231.

Hu, X., Haghjoo, K. \& Jordan, F. (1996). Further evidence for the structure of the subtilisin propeptide and for its interactions with mature subtilisin. J Biol Chem 271, 3375-3384.

Hube, B., Turver, C. J., Odds, F. C., Eiffert, H., Boulnois, G. J., Kochel, H. \& Rüchel, R. (1991). Sequence of the Candida albicans gene encoding the secretory aspartate proteinase. J Med Vet Mycol 29, 129-132.

Inouye, M. (1991). Intramolecular chaperone: the role of the propeptide in protein folding. Enzyme 45, 314-321.

Julius, D., Brake, A., Blair, L., Kunisawa, R. \& Thorner, J. (1984). Isolation of the putative structural gene for the lysine-argininecleaving endopeptidase required for processing of yeast prepro- $\alpha$ factor. Cell 37, 1075-1089.

Laemmli, U. K. (1970). Cleavage of structural proteins during the assembly of the head of bacteriophage T4. Nature 227, 680-685.

Lerner, C. G., Kobayashi, T. \& Inouye, M. (1990). Isolation of subtilisin prosequence mutations that affect formation of active protease by localized random polymerase chain reaction mutagenesis. J Biol Chem 265, 2085-2086.

Mclver, K. S., Kessler, E., Olson, J. C. \& Ohman, D. E. (1995). The elastase propeptide functions as an intramolecular chaperone required for elastase activity and secretion in Pseudomonas aeruginosa. Mol Microbiol 18, 877-889.

Monod, M., Togni, G., Hube, B. \& Sanglard, D. (1994). Multiplicity of genes encoding secreted aspartic proteases in Candida species. Mol Microbiol 13, 357-368.

Monod, M., Hube, B., Hess, D. \& Sanglard, D. (1998). Differential regulation of SAP8 and SAP9, which encode two new members of the secreted aspartic proteinase family in Candida albicans. Microbiology 144, 2731-2737.

Newport, G. \& Agabian, N. (1997). KEX2 influences Candida albicans proteinase secretion and hyphal formation. J Biol Chem 272, 28954-28961.

Ohta, Y., Hojo, H., Aimoto, S., Kobayashi, T., Zhu, X., Jordan, F. \& Inouye, M. (1991). Pro-peptide as an intermolecular chaperone: renaturation of denaturated subtilisin $\mathrm{E}$ with a synthetic propeptide. Mol Microbiol 5, 1507-1510.

Pfeffer, S. R. \& Rothman, J. E. (1987). Biosynthetic protein transport and sorting by the endoplasmic reticulum and Golgi. Annu Rev Biochem 56, 829-852.

Schaller, M., Schäfer, W., Korting, H. C. \& Hube, B. (1998). Differential expression of secreted aspartyl proteinases in a model of human oral candidosis and in patient samples from the oral cavity. Mol Microbiol 29, 605-615.

Schaller, M., Korting, H. C., Schäfer, W., Bastert, J., WenChieh, C. \& Hube, B. (1999). Secreted aspartic proteinase (Sap) activity contributes to tissue damage in a model of human oral candidosis. Mol Microbiol 34, 169-180.

Shinde, U. P., Liu, J. J. \& Inouye, M. (1997). Protein memory through altered folding mediated by intramolecular chaperones. Nature 389, 520-522.

Togni, G., Sanglard, D., Falchetto, R. \& Monod, M. (1991). Isolation and nucleotide sequence of the extracellular acid protease gene $(A C P)$ from the yeast Candida tropicalis. FEBS Lett 286, 181-185.

Togni, G., Sanglard, D., Quadroni, M., Foundling, S. I. \& Monod, M. (1996). Acid proteinase secreted by Candida tropicalis: functional analysis of preproregion cleavages in C. tropicalis and Saccharomyces cerevisiae. Microbiology 142, 493-503.

de Viragh, P. A., Sanglard, D., Togni, G., Falchetto, R. \& Monod, M. (1993). Cloning and sequencing of two Candida parapsilosis genes encoding acid proteases. J Gen Microbiol 139, 335-342.

Yaffe, M. P. \& Schatz, G. (1984). Two nuclear mutations that block mitochondrial protein import in yeast. Proc Natl Acad Sci U S A 81, 4819-4823.

Zhu, X., Ohta, Y., Jordan, F. \& Inouye, M. (1989). Pro-sequence of subtilisin can guide the refolding of denaturated subtilisin in an intermolecular process. Nature 339, 483-484.

Received 13 April 2000; revised 24 July 2000; accepted 9 August 2000. 